\title{
NOTAS SOBRE EL TEATRO EN SEVILLA DURANTE LA EXPOSICIÓN IBEROAMERICANA DEL AÑO 1929
}

\author{
Carolina RAMOS FERNÁNDEZ \\ Investigadora adscrita a la Universidad de Sevilla \\ info@carolinaramos.com
}

Resumen: La Exposición Iberoamericana de 1929 originó buena parte de la infraestructura teatral de la capital sevillana. Su estudio nos permite conocer interesantes proyectos que nunca se construyeron y las novedades que llegaban de Europa en arquitectura teatral.

\begin{abstract}
The actual theatral infrastructure in Seville originates with Iberoamerican Exposition in 1929. The study of this part of the history let us allows interesting projects which never built and the latest in European's theatral arquitecture.
\end{abstract}

Palabras clave: Teatro. Sevilla. 1929. Exposición Iberoamericana.

Key Words: Theatre. Seville. 1929. Iberoamerican Exposition. 
La capital sevillana de 1929, lugar de encuentro de personas llegadas de todo el mundo, no podía quedarse a la cola en la articulación de su oferta dramática que se estaba desarrollando en Europa. Así, los preparatorios para la celebración de la Exposición Iberoamericana conllevarían la realización de importantes proyectos que se vincularon con el desarrollo posterior del arte dramático en la ciudad, entre ellos la construcción del Teatro de la Exposición, actual Lope de Vega ${ }^{1}$. Y es que hay que tener en cuenta que, en este momento, el teatro acogía, además de actuaciones relacionadas con el mundo del espectáculo, actividades extraordinarias como funciones benéficas, vermuts y homenajes, que tenían como objetivo promover las relaciones sociales entre los asistentes, generalmente de clase social alta. Solían celebrarse a primera hora de la tarde y su recaudación generalmente era caritativa. Su importancia era tal que se abrían bonos para que los interesados se asegurasen la asistencia a ellas durante toda la temporada.

En general, y aunque el número dependa del momento del año en que nos encontremos, durante la Exposición la oferta teatral se mantiene en los tres teatros que existen (Cervantes, Del Duque y De la Exposición) y en la decena de cines o salas dedicadas a la proyección cinematográfica ${ }^{2}$, además de en los cinco espacios de variedades ${ }^{3}$ que acogían actuaciones musicales, cómicas y bailes de muy diversa naturaleza ${ }^{4}$. Estos espacios eran una nueva fórmula de los cafés-concierto de finales del siglo XIX que, según Francisca Íniguez Barrena, se habían realizado para quienes «pretendían alguna distracción después de cenar» (1999: 25).

Los programas teatrales del momento se desarrollaban en dos bloques ${ }^{5}$. El principal, se componía de la representación; el segundo, se iniciaba en el en-

\footnotetext{
1 Según Eduardo Rodríguez Bernal (1994), el origen de la propuesta de organizar una Exposición de esta naturaleza se encontraba en las necesidades de acometer reformas urbanísticas en la ciudad, ante todo los que estaban relacionadas con «la higiene y el asentamiento de una población más numerosa». Para ampliar datos ver el artículo «El Ayuntamiento y los partidos políticos sevillanos ante los inicios de la Exposición Iberoamericana (1909-1914)», La Exposición Iberoamericana de 1929, Separata de las Actas de las VI Jornadas de Andalucía y América, Sevilla: Consejo Superior de Investigaciones Científicas, 1987, 43-66.

2 Teatro Lloréns, Pathé, Salón Imperial, Teatro Rocío, Cine La Alicantina, Teatro Portela, Cine de la Huerta, Cine Nevería Universidad y Salas de espectáculos de las Galerías Comerciales en el sector sur de la Exposición Iberoamericana.

3 Kursaal Internacional, Variedades, Olimpia, Salón Barrera y Venta Eritaña. A finales de febrero del año 1930 se abrió el Circo Borza.

${ }^{4}$ La concepción espacial de los cinematógrafos es ampliamente criticada por dramaturgos y crítica. Un ejemplo es el argumento de Enrique Díez Canedo en su trabajo El teatro y sus enemigos.

5 Igual ocurre con las proyecciones de películas. En ese caso lo único que varía es la actividad principal que, en lugar de ser la representación de una obra de teatro, se compone de la proyección de un film.
} 
treacto, momento en que la actuación principal se completaba con la interpretación de alguna pieza musical, con el desarrollo de alguna charla poética ofrecida por algún conocido orador - generalmente relacionado con las artes escénicas- o con la declamación de alguna composición poética por alguno de los actores de la compañía.

Durante el verano, y dada la ausencia del aire acondicionado, los locales que tenían estructura de sala cerrada no presentaban actividad alguna. Ésta se concentraba en los cines de verano (llamados popularmente neverías) y en los partidos de pelota vasca.

\section{ESPACIOS Y LOCALIZACIÓN}

Los teatros de la ciudad se concentraban en las calles del centro histórico: Sierpes, Amor de Dios, Trajano, Puerta Osario, etc. Un ámbito que se había modificado con la Exposición Iberoamericana y que había ampliado los límites de la ciudad hasta el Parque de María Luisa. Allí se encontraban numerosos locales dedicados a las artes escénicas. Cada uno de ellos tenía una impronta diferente - generalmente la del empresario que lo gestionaba-, un funcionamiento y unos objetivos que cubrir en la demanda de espectáculos de los ciudadanos, tal y como a continuación se explica.

\subsection{Teatro de la Exposición}

Ubicado en el recinto de la Exposición Iberoamericana, este teatro comienza su actividad en la primavera de 1929, convirtiéndose desde entonces en el centro de ocio de las clases privilegiadas y la nobleza de la ciudad. Era el espacio donde celebrarían las ya mencionadas sesiones vermuts - conocidas también con el nombre de vermuts aristocráticos - y donde representarían sus trabajos las principales figuras de la escena nacional.

Tal y como destaca Julio Martínez Velasco, su construcción fue fruto de la coyuntura:

En principio no se pensó en construir un teatro dentro del recinto de la Exposición Iberoamericana, pero la idea se la sugirió a don José Cruz Conde su íntimo amigo y hombre entendido en cuestiones teatrales, el ingeniero de Montes Joaquín Gonzalo Garrido, que era, a su vez, empresario del teatro Mora, de Huelva (Martínez Velasco, 1999: 25). 
Desde su origen este teatro se convirtió en el Pabellón de Sevilla.

Obra del arquitecto Vicente Traver Tomás, el edificio constaba de cuatro plantas y un escenario dotado con adelantos modernos, además de una exuberante decoración barroca compuesta por pinturas, oro y tallas ${ }^{6}$. Sin embargo, la prensa destacó, como lo más novedoso, su alumbrado escénico; un trabajo para el que se había recurrido a los modelos alemán y estadounidense:

Se ha adoptado un sistema de distribución por cuatro colores: blanco, rojo, amarillo y azul y se ha procurado adaptar la instalación de la escena a los decorados que normalmente llevan las compañías de España, habiendo prescindido del alumbrado de horizonte, muy en boga actualmente, convencidos de su inutilidad al no contar con decorados apropiados (El Correo de Andalucía, 10-2-1929: 1 у 2).

Elementos que se ampliaban al alumbrado de socorro y a los cambios de focos que se harían mecánicos, a diferencia de la mayoría de los teatros españoles, donde el cambio era manual.

Pero lo que impactó a los cronistas fue la dotación de maquinaria para crear efectos especiales, ya que el Teatro de la Exposición contaba con un despliegue para imitar aullidos del viento, truenos, relámpagos, efectos de lluvia y movimientos del agua.

Como en la actualidad, el teatro estaba adosado al Gran Casino (que nacía como rotonda-vestíbulo del teatro), aunque poseía puerta propia y un hall porticado en la entrada donde se encontraban las dos taquillas en las que se despachaban las localidades ${ }^{7}$.

Desde sus inicios y hasta el final de la Exposición Iberoamericana la programación corría a cargo de la Comisión de Festejos de la misma, por

${ }^{6}$ El proyecto del Teatro de la Exposición se encargó en el año 1925 y su proyecto se aprobó el 13 de enero de 1927. De él se responsabilizó a Aníbal González, quien no lo realizó por discrepancias con la directiva de la Exposición Iberoamericana que le llevan a dimitir como director de las obras de la misma empresa. En este momento, según Víctor Pérez Escolano (1973), se optó por contratar a arquitectos menores que cumplieran plazos y presupuestos. Entre ellos, se encontraba Traver Tomás.

${ }^{7}$ En el Libro de Oro de la Exposición Iberoamericana se destacaba que el Gran Casino sería un espacio que se dotaría con «(...) amplísimas salas de fiestas, teatro y restaurant», teniendo en cuenta que su «construcción se ha inspirado en el periodo más clásico barroco andaluz» (p. XXV). Todo se enmarcaba en un presupuesto mayor, el de lograr que el ambiente artístico del Certamen estuviese «completo con exhibiciones de arte retrospectivo; brillantes colecciones de obras maravillosas de los artistas inmortales que elevaron el prestigio de España en los siglos de oro de nuestra historia» (pp. XXIV y XXV, del folleto depositado en la Hemeroteca Municipal de Sevilla, carpeta GK, 5). 
tanto del Ayuntamiento de la ciudad. Sin embargo, a finales del verano de 1930, Máximo Meyer, empresario que regentaba también el Teatro del Duque, se hizo cargo de la explotación comercial de este recinto que afrontaba una nueva etapa.

Ésta comenzaría el 20 de septiembre de ese mismo año, antes que los restantes teatros de la ciudad, con una gala a beneficio de la Asociación de la Prensa de Sevilla. Consciente del estatus que había alcanzado entre la población sevillana y de la dificultad que entrañaba su situación, Meyer mantendría el servicio de autobuses que comunicaban el Ayuntamiento con el teatro y el precio elevado de las entradas y de los abonos, cuya suscripción o renovación se publicaría en la prensa local, donde aparecían los nombres de los titulares para conocimiento de los ciudadanos.

Fue tal la curiosidad que despertó entre los aficionados este hecho que meses antes los periódicos daban cuenta de las negociaciones que estaban llevando a cabo sus responsables en Madrid con las compañías más importantes del momento ${ }^{8}$. Incluso se barajaron nombres de artistas que no llegaron a materializarse como Raquel Meller o La Argentinita que se había comprometido a representar una propuesta sobre El amor brujo, de Manuel de Falla.

Aunque poco a poco el cine se fue introduciendo en los espacios teatrales de la ciudad, el Teatro de la Exposición fue uno de los que más tardó en sucumbir, pues no incluyó muestras del séptimo arte hasta 1931. Sin embargo, desde el final de la muestra Iberoamericana, su peso en la actividad teatral de la ciudad fue decayendo paulatinamente. Así, al final de la temporada de otoño de 1930, se redujo drásticamente la presencia de grupos nacionales y se apostó por el trabajo de una compañía titular que, además, sólo ofrecía trabajos en sesiones vermuts a beneficio de la Asociación de la Prensa o de la cabalgata de Reyes Magos del Ateneo.

Desde las instituciones públicas se intentó paliar la crisis que afectaba a este teatro. De esta forma, y como se encontraba retirado del centro de la ciudad, una vez finalizada la muestra Iberoamericana, el alcalde, Conde de Halcón, ordenó la instalación de alumbrado público en los alrededores del edificio y su entorno para que los espectadores se animasen a acudir a sus instalaciones ofreciéndoles seguridad ciudadana. Desafortunadamente este gesto no fue suficiente para paliar su grave situación económica.

8 Muestra de ellos son los artículos siguientes: «El ciclo teatral durante la época de la Exposición de Sevilla», El Noticiero Sevillano, 22-2-1929, p. 4; «El teatro en Sevilla en la Exposición», en el mismo periódico, 3-3-1929, p. 1. 


\subsection{Teatro Del Duque}

Situado entre las calles Trabajo y Jesús del Gran Poder, fue uno de los espacios más activos de esta época. Ofrecía hasta cuatro funciones diarias y los domingos sumaba una quinta a primera hora de la sobremesa. De forma que sus sesiones podían comenzar a las 15:00 horas y acabar bien entrada la madrugada. Así, no son pocas las crónicas que hablan de la última Del Duque como cita imprescindible para los trasnochadores.

Su popularidad fue suficiente para que por su escenario pasaran las principales compañías de zarzuelas y revistas nacionales, aunque su sello de identidad fue la apuesta constante por los valores locales y la reiterada programación de espectáculos cómicos, protagonizados por personajes muy conocidos por el público. Fue el caso, por ejemplo, de Ramper, un artista polifacético que encabezaba una compañía de variedades, que permaneció largas temporadas con sus trabajos y que la crítica aplaudía como un hombre capaz de afrontar cualquier trabajo.

Se trataba de un edificio que tuvo varias transformaciones. Así, se edificó en el templo de San Miguel y se conoció como Teatro Circo del Duque. Su primera etapa comenzó en 1866 como circo; un año después, en 1867, se transformó en teatro, acogiendo espectáculos de zarzuela bufa. Y, finalmente, se abrió, ya como teatro, en 1876, espacio que se conserva hasta el momento. Una nueva etapa que, según Santiago Montoto, se hizo muy popular por acoger representaciones de género chico: «Al correr de los años, se cerró y se convirtió en un teatro alegre, predilecto de las clases populares. Constaba de tres plantas y no carecía de arte y riqueza» (Montoto, 1960: 379).

Su historia estuvo vinculada a los hermanos Álvarez Quintero de forma especial, pues acogió el estreno de su primer trabajo dramático, El peregrino (una zarzuela cómica en un acto, dividido en dos cuadros), el 6 de mayo de 1898.

Se demolió en 1938 y durante sus últimos años, como ocurrió en otros espacios de la ciudad, acogió, sobre todo, proyecciones cinematográficas. De hecho en las carteleras aparecerá como Cine Del Duque.

\subsection{Teatro Cervantes}

Baúl de sastre de la oferta espectacular, el teatro Cervantes, ubicado en la calle Amor de Dios, acogía en una misma temporada espectáculos de ópera, zarzuelas, teatro, circo o variedades. 
Su único criterio era sorprender al espectador y mostrar lo más novedoso o las creaciones más rancias de éxito asegurado. Poco a poco fue cediendo espacio al cine. De hecho, el propio Joaquín Gonzalo, propietario del teatro, anunciaría en septiembre de 1930 la próxima inauguración de un cine-teatro de talante monumental en la ciudad, pero sin adelantar su localización ni el presupuesto que manejaba para ello. Sin embargo, lo que acabó ocurriendo fue que acondicionó el local a las nuevas necesidades de los espectadores para proyecciones de cinematógrafo.

Su nombre completo era Gran Teatro Cervantes y se inauguró en el año 1873. Su construcción original fue como edificio de teatro-circo, siendo un proyecto del arquitecto Juan Talavera de la Vega, que, en los años cincuenta del siglo xx, se transformó en cinematógrafo 9 y que contaba con una capacidad para acoger a unos 2.500 espectadores, que se distribuían en tres grandes salas. Lo más novedoso era el hecho de que los palcos de sus pisos superiores volaban mucho sobre la sala, sin estar sostenidos por columnas.

Durante su prolongada vida, este teatro acogió estrenos vinculados al desarrollo de dramaturgos locales como los hermanos Álvarez Quintero: Belén, 12, principal (juguete cómico dado a conocer el 16 de mayo de 1888); o Esgrima y amor (otro juguete cómico que se estrenaba el 30 de enero de 1888).

En su sesión de estreno, en el año 1873, contó con una doble sesión compuesta por una versión de la comedia La dama boba, de Lope de Vega, y un drama en verso titulado El último día, original de los poetas sevillanos Luis Montoto y José de Velilla.

\section{OTROS ESPACIOS}

La ciudad contaba con otros espacios que pasaron a segundo plano en los años que nos ocupan. Generalmente se debió a que no desarrollaron actividad dramática alguna durante la Exposición Iberoamericana, bien porque no llegaron a realizarse, porque permanecieron cerrados, o porque se dedicaron a otras actividades. Incluso algunos de ellos no acogieron actividades teatrales hasta que finalizó la muestra internacional, pues formaban parte de los pa-

9 Según un proyecto de Antonio Delgado Roig y de Antonio Balbontín de Orta, que se realizó reduciendo la primera crujía, la fachada principal y los vestíbulos. 
pabellones de la misma. Todos ellos se incluyen en este apartado para completar el panorama teatral del momento y para valorar la herencia que dejó la Exposición en el ámbito que nos ocupa.

\subsection{Teatro San Fernando}

Era uno de los espacios clásicos de la ciudad, dado el tiempo que llevaba funcionando. No aparece en la reseña cronológica de estos dos años porque había sido clausurado al no reunir las normas de seguridad exigidas.

Se construyó a mediados del siglo XIX en la finca que ocupaba el Hospital del Espíritu Santo, en lo que vendría a ser hoy la calle Tetuán ${ }^{10}$. El edificio se debió a los ingenieros franceses Pablo Rohauly y Gustavo Sateneider y costó cuatro millones de reales.

Tenía capacidad para albergar a unos tres mil espectadores, lo que supuso que, en su momento, se convirtiera en el principal teatro de España y marcaba, según destaca Jean Sentaurens, una nueva concepción del lugar teatral: «la oligarquía sevillana, regenerada por el auge económico de la ciudad, al abrir en 1847 el suntuoso Teatro San Fernando, consigue imponer su propia concepción del lugar teatral, basada en la edificación de un teatro de ópera que le permitirá desarrollar holgadamente el complacido culto de su propia imagen» (Sentaurens, 1989: 71).

La contaduría de su teatro sirvió, en este momento, para comprar abonos para el Teatro de la Exposición durante el momento que nos ocupa. Al mismo tiempo se acometían las reformas necesarias para dotarlo de las medidas de seguridad oportunas. Según la prensa, se trataba de una intervención de encargo municipal que quería facilitar la salida del edificio.

Aunque no se abrió para la muestra iberoamericana, los responsables municipales no lo descartaron hasta el último momento.

Finalmente no fue así y los tres espacios que aquí se abordan acogieron la oferta dramática que, en buena medida, se hubiese derivado hacia este edificio, emblemático ya por entonces, de la capital sevillana.

\footnotetext{
${ }^{10}$ Se inauguró el 21 de diciembre de 1847 con la representación de la ópera Los Lombardos, de Verdi.
} 


\subsection{Teatro Infantil Juan de la Cueva}

Tras la Exposición Iberoamericana, el que hasta el momento había sido uno de los tres bloques del pabellón de los Estados Unidos se convirtió en el teatro Infantil Juan de la Cueva, que tuvo una actividad irregular en los años posteriores a la muestra y que contaba con una capacidad de 350 personas.

Era una creación municipal y del canónigo Antonio Mañes Jerez, quien ejerció como director del mismo. Su creación se fecha el 30 de enero de 1937, aunque se trae a estas páginas por ser herencia de la muestra Iberoamericana. Fue el primer espacio de la ciudad creado para acoger representaciones dirigidas al público infantil, aunque contaba con un antecedente directo como la actividad desarrollada en los colegios jesuitas de la segunda mitad de siglo $\mathrm{XVI}^{11}$.

Otros pabellones como el de Chile (que en su segundo piso había construido un teatro para 300 personas); o el de Portugal (que contaba con una sala para 250 personas), se perdieron con el final de la muestra, posiblemente por falta de previsión.

\subsection{Luca de Tena}

Aunque en la prensa se anunció como «de inminente construcción $»^{12}$ no llegó a realizarse durante la Exposición Iberoamericana. No era la primera vez que ocurría, pues ya, en 1915, José Esplau Muñoz había intentado desarrollarlo sin suerte ${ }^{13}$. Sin embargo, en los años cincuenta, el grupo Prensa Española retomaría la iniciativa, ejecutando el que, finalmente, se conoció como teatro Álvarez Quintero ${ }^{14}$.

11 Aguilar Piñal (1974: 8) destaca cómo en la segunda mitad del siglo XVI, «el teatro vino a ser considerado como escuela de alta formación cultural, imponiéndose la costumbres de las representaciones escolares, particularmente en los colegios de jesuitas» (p. 8). Según el autor, «frente a los 'corrales' de ambiente popular, los colegios ofrecían a sus distinguidos alumnos la posibilidad de entrar en contacto directo con los autores clásicos». Y añade que, entre estos centros escolares, destacó, por su actividad, el de San Hermenegildo.

12 El Liberal, 16-1-1929, p. 3

13 Según el estudio Arquitectura teatral y cinematográfica. Andalucía 1800-1990, el proyecto de teatro y viviendas que finalmente se llevó a cabo lo encargó Prensa Española al estudio OTAISA y fue el único teatro de nueva planta que se construyó en la ciudad entre los años 1931, fecha en que se realizó el Coliseo España. El autor del proyecto final fue Felipe Medina Benjumea.

${ }^{14}$ Como destaca Santiago Montoto (1960: 380), se abrió el 12 de octubre de 1953, con la puesta en escena de la comedia Ventolera, de los Hermanos Álvarez Quintero; y con una loa a los autores, original del marqués Luca de Tena. 
El Luca de Tena era un proyecto del arquitecto Aníbal González y, según la prensa del momento, se iba a convertir en «uno de los más bellos y lujosos de Europa», pues estaba previsto que, para su realización, se emplearan los materiales «más artísticos y costosos de producción nacional» ${ }^{15}$. Un edificio con el que el director del periódico $A B C$, Torcuato Luca de Tena, quería agradecer a Sevilla su apoyo y constantes muestras de cariño ${ }^{16}$.

El nuevo teatro se iba a construir en la calle Laraña, frente al edificio que ocupaba la Universidad en este momento ${ }^{17}$. La nueva edificación tendría una fachada de 21 metros de altura y estaría orientada al mediodía, quedando en un lateral la calle Arguijo, ocupando una superficie total de 1.180 metros cuadrados.

Para su interior, Aníbal González había diseñado una sala con forma de medio círculo prolongado (herradura) que, según la prensa: «Para su proporción entre su longitud y su anchura se ha tenido presente la comparación de los principales teatros, especialmente los europeos, y con arreglo a este estudio se han determinado las de 19,40 por 18,30 , respectivamente» ${ }^{18}$.

La fachada principal del teatro aparecía, en el proyecto, dividida en tres partes: una central, que correspondería al pórtico de 13,50 metros de longitud por 6 metros de anchura, que estaría preparada para acoger la entrada de autos; y dos laterales, cada una de las cuales contendría un vestíbulo de ingreso y una escalera que llegaría hasta la altura de la planta del edificio.

El vestíbulo principal ocuparía 13,50 metros de longitud por 9 metros de altura y estaba previsto que se uniera al pórtico por medio de cinco arcos. Además, para facilitar la entrada de los espectadores, el proyecto contaba con una entrada lateral con un vestíbulo y un acceso independientes. De esta manera los peatones podían hacer su entrada en el edificio sin necesidad de cruzarse con los automóviles. Para ello, y frente a esta entrada, se dispondría una sala, vinculada al vestíbulo, que el público podría utilizar también para acceder al edificio. Por su parte, la entrada a los asientos del anfiteatro principal y segundo piso se había previsto de forma independiente por medio de dos vestíbulos con escaleras laterales que se unieran con la sala por amplias y rectas galerías.

\footnotetext{
15 Todas las citas de esta frase provienen del diario El Liberal, 16-1-1929, p. 3.

16 Puesto que, según mis datos, no se ha recogido en ningún lugar el proyecto y dado el interés que tiene éste, me extiendo en su reseña ofreciendo los datos de primera mano.

17 La actual Facultad de Bellas Artes.

18 El Liberal, 16-1-1929, p. 3
} 
Frente al vestíbulo principal del coliseo se pretendía construir una gran escalinata que, según el propio arquitecto, «salvaba la diferencia de rasante entre el exterior y la altura del patio de butacas» ${ }^{19}$.

El teatro ofrecería, entre sus servicios generales: galerías de comunicación, guardarropas, servicios higiénicos, despachos de billetes, contaduría y salones para el público. Y para que pudiera usarse durante todo el año, se le iba a dotar de instalación de calefacción y de ventilación.

Las escaleras - en el proyecto se contemplaba la construcción de dosse situarían a ambos lados de la fachada principal y permitían el acceso al entresuelo. Las galerías de comunicación se situarían en el entresuelo y podían extenderse por el frente del vestíbulo hacia la derecha y la izquierda del mismo, pudiendo, en caso de necesitarse, establecer un enlace inmediato con las escaleras de los anfiteatros. De otro lado, los pasillos exteriores de comunicación tendrían una anchura de 1,50 metros y comunicarían con la calle Arguijo por medio de dos grandes ventanas-puertas con disposición para utilizarlas en caso de alarma. Finalmente, los despachos de billetes se situaban en los vestíbulos secundarios y podían utilizarse, indistintamente, desde el interior del edificio o desde el exterior. Por su parte, la contaduría del teatro se establecía en el lado de la calle Arguijo, cerca del vestíbulo e inmediata al despacho de billetes.

Pensando en la relación social que implicaba ir al teatro, el arquitecto situó, en la planta del anfiteatro principal, ocupando la misma superficie que en los pisos inferiores correspondientes al pórtico, un salón de 13,50 por 6 metros. Teniendo esta iniciativa una modificación en la última planta que daba como resultado un salón de 12,80 de anchura en dos crujías por 13,50 de longitud.

El nuevo espacio contaría con 1.238 localidades, que se distribuían por plantas de diferentes formas y con acondicionamientos también distintos. Así, el piso bajo contaba con 16 dieciséis filas de butacas y plateas, lo que arrojaba un total de 318 localidades. Unas butacas que perseguían, ante todo, la comodidad de los espectadores, para lo que la anchura de paso era de un metro (quince centímetros más de lo que marcaba el reglamento del 19 de octubre de 1913). Además, el proyecto disponía en el patio del mismo edificio, un paso central de un metro de ancho y dos laterales, inmediatos a las plateas, de 0,80 metros, cada uno. Al patio de butacas se podía acceder a

19 Ibídem. 
través de tres entradas: una central y dos laterales de 1,80 metros de anchura.

Las plateas se colocarían a ambos lados del patio y al fondo siendo su número total de cinco en cada uno de ellos. Estaba previsto que la primera de la derecha se reservara para la propiedad y, para ello, se le dotaría con un acceso directo desde la calle mediante una escalinata. En su interior contendría un pequeño gabinete ante-platea que comunicaría con la sala y el escenario, además de un cuarto de aseo. Finalmente, el entresuelo, se dedicaría a butacas que se distribuirían por todo el frente - espacio que ocuparía también un voladizo de 4,50 metros - y palcos laterales. En este sentido, se preveía la construcción de cuatro filas de butacas de diferente altura y un número total de 117 asientos.

Los palcos previstos eran doce y se dispondrían la mitad a cada uno de los lados. Estos espacios estaban diseñados con amplitud e incluyendo un antepalco. El acceso se haría por el pasillo exterior que se extendería al anfiteatro principal por el fondo hasta alcanzar el límite marcado por el muro del vestíbulo general. Para ello, se dispondría de asientos sobre gradería, con una adecuada inclinación para favorecer la visibilidad de quienes los ocuparan.

También contemplaba la realización de una fila de palcos delanteros y, en la parte del frente, cinco filas más que se irían convirtiendo en cuatro, tres y dos, a medida que se agotara el espacio disponible. El número de butacas previsto para esta planta era de 281. Para facilitar el acceso al anfiteatro se construirían cinco puertas y escalinatas que salvaran las diferentes alturas.

En el anfiteatro del segundo piso se pensaba adoptar una disposición diferente a las reseñadas hasta el momento con la intención de ampliar la capacidad del nuevo espacio teatral. Este espacio acogería localidades de delantera, tres filas en el frente y dos en los laterales que se alargarían hasta la gradería por el fondo con filas rectas que se colocarían en seis gradas. Para resolver la entrada y salida de público se construirían puertas y los asientos totales de este piso sumarían los 390 .

En lo que respecta a la escena hay que señalar que, para sus tres partes fundamentales: foso, escenario y telar, se había destinado un espacio de 10,50 metros de superficie, ocho metros de altura y un cuatro por ciento de inclinación. El telar, por su parte, ocuparía 12 metros. Además, el escenario se comunicaría con la sala por una sola puerta de 0,75 metros, con hojas de hierro; y con el exterior, por una de tres metros de anchura que conduciría directamente a la calle Arguijo. Sin olvidar en este sentido a los artistas, que accederían al escenario por otra puerta que sólo emplearían ellos. 
Precisamente para las compañías artísticas se había diseñado un departamento compuesto por un saloncillo y diferentes servicios. Estas dependencias se situarían en la planta baja, aunque también se dispondría de cuatro plantas donde se distribuirían los cuartos con arreglo a las categorías profesionales.

Como ya se destacó al inicio de esta reseña, los materiales que se proyectaron utilizar en la construcción de este teatro eran usuales y corrientes de la localidad, puesto que se quería realizar un teatro entroncado con su tradición arquitectónica ${ }^{20}$.

Para el interior, se había diseñado la realización de un forjado de cemento armado; en la cubierta de sala se emplearía una armadura de hierro y cristal movible y fácilmente trasladable para dejar libre la circunferencia de diez metros de diámetro. Además, se pensaba realizar una claraboya de las mismas dimensiones que dejara la sala en perfecta comunicación con el exterior.

Para la decoración, Luca de Tena y Aníbal González querían recubrir el techo del vestíbulo de artesonado de madera policromado y dorado; emplear el ladrillo para los exteriores. Un material que se limpiaría, cortaría - con arreglo a los perfiles especiales de determinados espacios del edificio- $-\mathrm{y}$ se tallaría siguiendo las prácticas originales de la ciudad. En la misma fachada se había previsto emplear el barro cocido como material fundamental y motivos sevillanos, realizados en hierro forjado, madera tallada, paramentos revestidos de cerámica vidriada, techos de madera policromada y dorada, mármoles de diferentes colores, entre otros.

La muerte del conocido arquitecto —el 1 de junio de 1929- y del mecenas —el 15 abril de 1929—, y los múltiples problemas a los que tuvo que hacer frente la Exposición Iberoamericana, imposibilitaron la realización de tan ambicioso proyecto, que retomaría la ciudad años más tarde.

\subsection{Teatro Reina Mercedes}

En enero de 1929, la prensa se hacía eco de la realización de un proyecto teatral: el de la construcción del Gran Teatro de la Avenida Reina Mercedes.

20 Víctor Pérez Escolano (1973: 78) señala que en este momento «la amplia producción edificatoria» de Aníbal González se realizaba « (...) con base en el desarrollo de las industrias básicas y tradicionales de la construcción, las del ladrillo, de la cerámica vidriada y del hierro fundido y forjado, aparte las de la cal, el yeso y la madera tallada». 
Se trataba de una propuesta que tenía previsto inaugurarse en el otoño de ese mismo año y que, ya a finales de enero, se encontraba «muy adelantado» ${ }^{21}$ para los plazos marcados. Sin embargo habría que esperar hasta el año 1931 para que esto se produjera. Su nombre fue el de teatro del Coliseo o Coliseo España.

El proyecto lo realizó Ildefonso Marañón y la propuesta la habían diseñado dos arquitectos: José y Aurelio Gómez Millán. Se trataba de un edificio de grandes dimensiones - unos mil cien metros cuadrados - , en el que primaba el uso del ladrillo limpio en principio ideado para acoger representaciones teatrales, pero que, posteriormente, dada la riqueza de su construcción, y de su situación se dedicó al cinematógrafo.

La ubicación de la fachada principal correspondía a la calle Santo Tomás y aparecía rematada por dos amplios torreones con artísticas agujas de hierro forjado. En ambos torreones se pintaron los artesonados de estilo mudéjar. Además, la obra se complementaba con la colocación de unos faroles de hierro en los pilares de las terrazas que daban a la avenida Reina Mercedes y de bronce en las puertas de acceso a los vestíbulos, donde también aparecían unas vidrieras artísticas. En las terrazas se instaló un alumbrado indirecto, compuesto de reflectores, que se proyectaba en la fachada y los torreones durante la noche.

El espacio se dividía en un patio de butacas - sin platea-, que tenía capacidad para albergar a unas novecientas cincuenta personas; un amplio anfiteatro frontero que comprendía los pisos entresuelo y principal; ocho palcos a cada uno de los lados del piso (treinta y dos en total); anfiteatro de doscientas butacas y palcos de ciento noventa y dos butacas; y una segunda grada en el patio tercero con capacidad para setecientas localidades. En total 2.100 localidades.

Su escenario tenía nueve metros de embocadura y un fondo de once metros, cinco más de los que se pensó inicialmente. Para acceder a la sala contaba con once puertas (una más de las reglamentarias), todas ellas con hojas de madera tallada. Los cortinajes y el telón iban a ser de damasco rojo y las butacas de color caoba, tapizadas en terciopelo cortado, también de color rojo.

El recinto contaba, además, con calefacción, que se hacía por aire caliente con arreglo a los procedimientos más modernos del momento, mediante

${ }^{21}$ El Liberal, 30-1-1929, p. 1. 
una instalación que servía también para refrigerar durante el verano. El aire se renovaba en todo momento y hasta dos veces por hora.

El proyecto tenía instalaciones para casos de incendio, como bocas de agua en todos los pisos, en el foso y en los telares; y con extintores que se repartían por todo el recinto.

\section{CALENDARIO, PRECIOS Y SESIONES}

La peculiaridad del calendario sevillano - con su acumulación de fiestas en la primavera - obliga a los espacios dedicados al espectáculo teatral a organizar su oferta de una manera distinta a la del resto de España. De esta manera, la temporada comenzaba en otoño, con la llegada de la Feria de San Miguel, en los últimos días de septiembre, y se prolongaba hasta diciembre. Desde ese momento, y con la llegada de los primeros días de enero, arrancaba la temporada de invierno que se desarrollaba hasta el mes de marzo, cuando tomaba el relevo la temporada de primavera. Un trimestre complicado para programar al celebrarse la Semana Santa, la Feria de Abril y las festividades del mes de mayo. Finalmente, la cartelera iniciaba la temporada de verano que, dadas las altas temperaturas que se alcanzaban en las calles sevillanas, en este momento se dilataba solamente - y siempre en casos excepcionales - hasta la primera quincena del mes de julio. Un ejemplo lo protagoniza el Teatro de la Exposición, que, confiando en el apoyo de promoción que le ofrecía la cercanía de la muestra Iberoamericana, prolongó la temporada veraniega de ese año hasta bien entrado el mes de julio. Un hito que no volvería a repetirse en el periodo que nos ocupa.

Según lo expuesto, no extraña que muchas reseñas y comentarios que aparecen en la prensa afirmasen que la temporada que iba de enero al sábado de Gloria era mala para hacer taquilla, mientras que la que iba de septiembre a diciembre concentraba la mayor parte de la recaudación anual en los espacios escénicos.

Una peculiaridad en la cartelera de los años que nos ocupan es que cada uno de los teatros de la ciudad ofrecía un número distinto de sesiones. Aunque esta decisión recaía sobre el empresario, muchas compañías negociaban el número de trabajos que ofrecerían cada día al público. De esta forma, encontramos que el Teatro del Duque podía programar, en plena temporada, hasta cinco funciones; mientras que el Teatro de la Exposición ofrecía sólo una y, como excepción, llegaba a la segunda el domingo. 
Aún así se pueden distinguir dos tipos de funciones: las puramente teatrales y las híbridas. En el primero de los casos se encontraban, sobre todo, el Teatro de la Exposición y el Teatro Cervantes. Ambos ofrecían sólo espectáculos dramáticos, que comenzaban a primera hora de la noche, en torno a las 22:00 horas, aunque podían multiplicarse hasta alcanzar las tres sesiones diarias, distribuyéndose de la siguiente manera: una de tarde, otra de noche y una última de madrugada ${ }^{22}$. En cuanto al Teatro del Duque, hay que tener en cuenta que también ofrecía funciones puramente teatrales y que solían distribuirse de la siguiente manera: una primera, a partir de las 19:30 horas; una segunda, que se situaba en torno a las 21:00 horas y una final, que comenzaba en torno a las 22:30-23:00 horas. Esta oferta horaria, sin embargo, variaba en función del día de la semana que se tratara.

Todos los espacios de ocio de la ciudad ampliaban su oferta los domingos para lograr la atención del público en el día de descanso ${ }^{23}$. Así, los domingos, el Teatro del Duque ofrecía hasta cuatro sesiones al incluir una primera a las cuatro de la tarde; el Teatro Cervantes podía llegar a ofrecer tres: a las 18:00, 21:00 y 22:45 horas, aunque podía variar entre dos y tres; y el Teatro de la Exposición llegaba a las dos: una a las 18:00 y otra a las 22:00 horas, aunque también podía ser la última su único su reclamo. En el caso de las programaciones híbridas (que podían darse en cualquier teatro) hay que destacar cómo el cine era, generalmente, el género más utilizado para combinar con las representaciones, aunque también podían hacerse con actuaciones musicales, charlas poéticas y conciertos.

Proyecciones de películas o documentales de muy diversa naturaleza completaron durante estos años las sesiones de ocio de los espectadores. En unos casos, se trataba simplemente de largometrajes que protagonizaban las estrellas más conocidas del star system norteamericano; en otros, se trataba de noticieros que las productoras realizaban en torno a sus nuevos proyectos o a los protagonistas de un negocio que comenzaba a florecer en Europa con la misma fuerza que lo había hecho años antes en los Estados Unidos. Estos documentales fueron adquiriendo un tono distinto a medida que las circunstancias socio-políticas iban cambiando.

\footnotetext{
22 Según Francisca Íñiguez Barrena (1999), esta distribución de las sesiones teatrales era herencia de la distribución que se desarrolla en la escena durante el último tercio del siglo XIX, momento en que se inicia el café teatro.

23 Según Jorge Uría (2001), el Reglamento del 19 de abril de 1905 había desarrollado la Ley de Descanso Dominical de 1904, lo que supuso un avance en la ordenación del trabajo de los españoles.
} 
Como se ha comentado, las funciones de tarde eran conocidas como sesiones vermuts y, en teatros como el de la Exposición, solían venderse bonos de temporada que incluían diez entradas para acudir a estas funciones. Generalmente eran válidas sólo para algunos días de la semana, en los que la cartelera tenía que buscar otros atractivos para incitar al público a su asistencia. Los martes y los viernes eran los días indicados para su desarrollo, aunque, en determinadas fechas del año, podían multiplicarse. De hecho, así ocurrió cuando la Asociación de la Prensa de Sevilla llegó a un acuerdo, en noviembre de 1930, con el empresario del Teatro de la Exposición para desarrollar funciones en las que se representaran las obras de mayor éxito y otras populares $^{24}$. Para su desarrollo contaría con la compañía titular del coliseo.

Entre los días de la semana había preferencias y así las compañías sabían que debían concentrar sus esfuerzos en los encuentros de fin de semana, de viernes a domingo, tanto por motivos sociales, como por ser el de descanso para la mayoría del público, hecho que hacía que fuera el de mayor oferta dramática de la semana:

El jueves no debía ser día de gran afluencia frente al viernes que era de abono. Los viernes se institucionalizaron como el día en que la gente más distinguida iba obligatoriamente al teatro. También se utilizaba la denominación 'día de moda'o 'viernes blanco'. Por lo general se elegían obras que no dañaran la sensible epidermis de la clase media (Menéndez Onrubia, 1984: 62).

Hay que señalar también la diferencia entre las sesiones y las sesiones dobles. Las primeras hacían referencia a piezas con una duración de una hora; y las segundas aparecían cuando la función se alargaba porque la pieza tenía dos actos o más. Este tipo de trabajos era herencia de la zarzuela chica y ofrecía momentos para el lucimiento de las primeras figuras de las compañías.

Para su desarrollo, los intérpretes hacían uso de disfraz y de todas las posibilidades de su cuerpo (movimiento, voz y gesto), un hecho que potenciaba sugerencias picaronas. Aspecto que tomó relevancia en los años que nos ocupan y que definirán el trabajo de buena parte de las actrices del momento.

En cuanto al precio de las localidades, hay que señalar que no era el mismo en todos los teatros. Así, en el Teatro de la Exposición una butaca de patio costaba 5 pesetas y 2 pesetas la de anfiteatro. Por su parte, el Cervantes

${ }^{24} \mathrm{El}$ acuerdo se da a conocer en la prensa local. En los artículos, incluso se da a conocer una lista de títulos que se van a llevar a escena (ABC, 23-11-1930, p. 39). 
fijaba sus entradas populares entre las 2 y las 3 pesetas. Cifras que ofrecen la primera clave de la explosión que vivió el cine en la ciudad con la llegada del sonoro, pues el precio de los billetes rondaba la peseta (media peseta si era cine de verano) y facilitaba el acceso de las capas con menor capacidad económica ${ }^{25}$.

Así, el espectáculo teatral se encontraba en un momento crucial. Desde la última década del siglo anterior había vivido una expansión y había propiciado numerosos estrenos, lo que había llevado consigo la articulación de la industria espectacular. Ello se tradujo en el desarrollo de determinados géneros, en la subida al escenario de símbolos de los nuevos tiempos donde el sexo y el teatro del equívoco (que se materializaron en cuplés, revistas y un vestuario que para muchos fue casi-pornográfico) y en los números cortos y variados que se iban sucediendo con rapidez sobre el escenario. Pero también en el desarrollo de nuevos espacios con más posibilidades para las compañías que investigaban en el escenario con nuevos elementos técnicos. De ahí, la importancia de los nuevos espacios y de la renovación teatral, como ocurrió en el caso sevillano que hemos descrito.

\section{REFERENCIAS BIBLIOGRÁFICAS}

AA. VV. (1929). Libro de Oro de la Exposición Iberoamericana. Sevilla: Ayuntamiento de Sevilla.

- (1987). La Exposición Iberoamericana de 1929. Sevilla: Escuela de Estudios Hispano-Americanos.

- (1990). Arquitectura teatral y cinematográfica. Andalucía 1800-1990. Sevilla: Consejería de Cultura y Medio Ambiente.

- (1999). Catálogo de autores dramáticos andaluces (1898-1998). Vol. III. Sevilla: Centro de Documentación de las Artes Escénicas, Consejería de Cultura.

- (2001). El teatro de humor en la guerra y la posguerra española (19361948). Cádiz: Universidad de Cádiz, Fundación Pedro Muñoz Seca.

ANÓNIMO (1929a). «En breve comenzará la construcción del Teatro Luca de Tena en Sevilla». El Liberal, 16-1, 3.

\footnotetext{
${ }^{25}$ Todas estas afirmaciones tienen como fuente el artículo de Antonio De Hoyos y Vinent (1930).
} 
ANÓNIMO (1929b). «El gran teatro de la Avenida Reina Mercedes se inaugurará probablemente en la temporada de otoño». El Liberal, 30-1, 1.

- (1929c). «El ciclo teatral durante la época de la Exposición de Sevilla». El Noticiero sevillano, 22-2, 4.

- (1929d). «El teatro en Sevilla en la Exposición». El Noticiero Sevillano, 3-3, 1 .

- (1930). «Vermoths líricos en el teatro de la Exposición. A beneficio de la Asociación de la Prensa se representarán las obras de mayor éxito de la temporada». $A B C, 23-11,39$.

Aguilar Piñal, Francisco (1974). Sevilla y el teatro en el siglo XVIII. Oviedo: Universidad de Oviedo.

Álvarez Quintero, J. y S. (1982). Obras completas. Madrid: Espasa Calpe.

Colón Perales, C. (1983). El cine en Sevilla (1929-1950). De la Exposición y la llegada del sonoro a la posguerra. Sevilla: Ayuntamiento de Sevilla.

DíEZ CANEDO, E. (sin fecha). El teatro y sus enemigos. Obra digitalizada por El Colegio de México (Antigua Casa de España) y reproducida por la Biblioteca Virtual Cervantes en http://cervantesvirtual.com.

Hoyos y VinenT, Antonio de (1930). «De, en, por, sin, ser, sobre el cinematógrafo. El tósigo del cine sonoro». $A B C, 8-7,10-11$.

ÍñgUEZ BARRENA, F. (1999). La parodia teatral en España (1868-1914). Sevilla: Universidad de Sevilla.

Martínez Velasco, J. (1999). El teatro Lope de Vega. Sus primeros setenta años. Sevilla: Área de Cultura del Ayuntamiento de Sevilla.

MENÉNDEZ OnRUBIA, C. (1984). El dramaturgo y los actores. Epistolario de Benito Pérez Galdós, María Guerrero y Fernando Díaz de Mendoza. Madrid: CSIC.

Montoto, S. (1960). «El teatro, el baile y la danza en Sevilla». Archivo Hispalense 103-4, 371-385.

Pérez Escolano, V. (1973). Aníbal González. Sevilla: Diputación Provincial de Sevilla.

RODRÍGUEZ BERnAL, E. (1994). Historia de la Exposición Iberoamericana de Sevilla de 1929. Sevilla: Ayuntamiento de Sevilla. 
Sentaurens, J. (1989): «Le lieu théâtral à Séville au XIX ${ }^{\mathrm{e}}$ siècle. Tradition et modernité». Bulletin Hispanique (Bordeaux) 91.1, 71-110.

URÍA, J. (2001). «El camino del ocio de masas. Las industrias culturales en España antes de 1914». En Trabajo y ocio en la Época moderna, Luis A. Ribot García y Luigi de Rosa (eds.), Colección El Río de Heráclito. Madrid: Actas. 